\title{
INTEGRAL CHARACTERISTICS OF STABILITY OF COAL-WATER SLURRIES AND COAL-WATER SLURRIES CONTAINING PETROCHEMICALS BY EVALUATION OF SEPARATION INTO LAYERS
}

\author{
Margarita A. Dmitrienko ${ }^{1 *}$, Galina S. Nyashina ${ }^{1}$, Ksenia Yu. Vershinina ${ }^{1}$, and Sergey Yu. \\ Lyrschikov $^{1}$
}

${ }^{I}$ National Research Tomsk Polytechnic University, 634050 Tomsk, Russia

\begin{abstract}
For wide use of coal and oil processing wastes in heat power industry we investigated the structural stability of coal-water slurries (CWS) and coal-water slurries containing petrochemicals (CWSP). Three methods of evaluating slurry stability were considered. The method of evaluation of separation (into layers) of the slurry was chosen to determine the stability of fuel compositions based on bituminous and brown coal, filter cakes of bituminous coals, waste motor, turbine, transformer, compressor oils, oil, oiled mixture and mazut. The experiments shown, that the addition of waste oils (with mass fraction of $10 \%$ ) to investigated fuel compositions leads to increase of slurry segmental stability is almost by 2 times.
\end{abstract}

\section{Introduction}

The technologies of production, transport and combustion of coal-water slurries (CWSs) [1] and coal-water slurries containing petrochemicals (CWSPs) [2-4] are urgent and modern direction of development of thermal power industry. CWS is a composite fuel that has two main components - coal (or wastes of coal processing) and water. The main components of CWSP are water, coal (or wastes of coal processing) and flammable liquid (for example, waste motor oil or oil sludge). The component base for production of CWSs and CWSPs is large and annually intensively increases. The prospects and possibility of using unclaimed coals and coal processing wastes for production of CWSs and CWSPs allow solving the issues of efficient use of resources [5]. In addition, non-energy brown coals, solid residuals of coal and oil processing can be a combustible basis for slurry fuel. These wastes pose a significant environmental risk, and their storage requires considerable expenses. For preparing various compositions of CWSPs [2-4] the wastes of oil production and refining, pyrolysis pitches of various industries, waste motor, transformer, turbine oils and other liquid organic wastes can be used. Liquid fuel components are applied in a composition of

\footnotetext{
*Corresponding author:mad2@tpu.ru
} 
fuel slurry as for changing the ignition and combustion characteristics, and as a plasticizing and stabilizing additive.

Low rates of slurry stability values, high ash content of fuel components, sufficiently low efficiency of known reagents - plasticizers and stabilizers [6] are one of the basic difficulties for a wide use of CWSs and CWSPs in the energy industry. In terms of the relative coal density is greater than one, and the coal particle diameters are significantly larger than that of colloid, the preservation of stable structure of fuel slurry due to Brownian motion is impossible. Thus, it is difficult to prevent sedimentation of coal particles of CWSs and CWSPs.

Currently quite a lot of experimental studies [7-17] on determining coal slurries stability using different methods for its assessment were carried out. The method of evaluation of separation (into layers) of the slurry [7-10], the method of penetration of the glass rod [11-13] and translucence method [14,15] are along the best known.

The evaluation of slurry stability by the method of layers separation consists in measuring the volume of the layer separated from the bulk during storage or transport of slurry. Thereby one of the following indicators is calculated:

1) stability index:

$$
Y_{1}=\frac{v_{c}}{v_{0}}
$$

where $v_{0}, v_{c}$, respectively, the volume of fuel filled into vessel (measuring cylinder) and the volume of eventually separated layer;

2) mass fraction [9]:

$$
\gamma=\frac{w_{2}-w_{0}}{w_{1}-w_{0}}
$$

where $w_{1}$ - initial mass of the slurry together with the measuring cylinder; $w_{2}$ - mass of the deposited (dark) layer together with the measuring cylinder; $w_{0}$ - mass of the measuring cylinder;

3) the average segmentation rate [10]:

$$
r=\frac{\alpha_{1} \cdot\left(c_{0}-c_{1}\right)}{t \cdot \alpha_{0}\left(100-\mathrm{c}_{0}\right)} \cdot 100 \%,
$$

where $\alpha_{0}-$ initial mass of slurry; $\alpha_{1}-$ mass of separated liquid layer; $c_{0}-$ initial coal concentration; $c_{1}$ - coal concentration in separated liquid layer; $t$ - time of slurry holding.

The method for evaluation of CWS stability, which is based on using glass (or metal) rod (diameter $d=4-5 \mathrm{~mm}$, mass $m=20 \mathrm{~g}$ ) [11-13] is consists in the following. The test fuel slurry is poured into a measuring cylinder and kept for 72 hours. Then the glass rod falls spontaneously from the surface of the slurry to the bottom of the cylinder. The separation into layers for slurry with a high stability does not occur and the rod can easily reach the bottom of the cylinder. For suspension with a worse stability the rod penetrates worse the solid layer of sediment. The penetration coefficient is calculated:

$$
\gamma=\frac{d}{d_{t}} \cdot 100 \%
$$

where $d$ - the distance that the rod was moved; $d_{t}-$ the maximum distance at which the rod can move. This coefficient ranges from 0 to $100 \%[11,12]$.

The translucence analysis method is based on the change of intensity of the transmitted light over the entire length of the vessel containing fuel slurry [14]. Spectrum of light transmittance can be continuously obtained as along the entire fuel volume, and as in one of its points. In the studies [14-17] the dispersion stability analyzer is used for the translucence analysis method. This analyzer provides a classification and quantitative characterization of the process of separation, which determines the stability of the 
dispersions and storage time. Such analyzers can be used to optimize processes of CWSs and CWSPs production and quality control, as well as for research.

In the present work the method of evaluation of slurry separation (into layers) [7-10] for determining the stability of CWSs and CWSPs was chosen. The investigated fuel compositions have a low viscosity and using the method of penetration of the glass rod [1113] is impossible because the rod completely goes down to the bottom of the cylinder for all the investigated slurry compositions. And the main constraint of translucence method $[14,15]$ is the necessity to purchase specialized expensive equipment (dispersion stability analyzer).

The purpose of the present work is the experimental determination of integral characteristics of stability of CWSs and CWSPs using the evaluation method of slurry separation into layers.

\section{Experimental procedure}

The determination of slurry stability was carried out for several compositions of CWSs and CWSPs. Waste motor, turbine, transformer, compressor oils, oil ("Gerasimovskoye" oil deposit, Tomsk region, Russia), oiled mixture and mazut were used as a liquid combustible component. Filter cakes (wet residue of bituminous coal enrichment by flotation), brown coal of B2 rank (Borodino deposit of Krasnoyarsk region, Russia), bituminous coal of D rank (Gramoteinskaya mine of Kemerovo Region, Russia). We used filter cakes from coalpreparation plant of Kemerovo region (Russia): filter cake of K rank (from "Severnaya" plant); filter cake of SS rank (from "Chernigovskaya-Koksovaya" plant); filter cake of T rank (from "Kaltanskaya-Energeticheskaya" plant); filter cake of G rank (from plant of the mine named after Kirov); filter cake of D rank (from "Gramoteinskaya" plant).

\subsection{The evaluation of stability index}

The stability index was determined for the following compositions:

$-100 \%$ filter cake of $\mathrm{T}$ rank (moisture content $39.1 \%$ );

$-100 \%$ filter cake of $\mathrm{K}$ rank (moisture content $43.5 \%$ );

$-100 \%$ filter cake of SS rank (moisture content $37.9 \%$ );

$-100 \%$ filter cake of $\mathrm{G}$ rank (moisture content $53 \%$ );

$-100 \%$ filter cake of D rank (moisture content $56.8 \%$ );

$-90 \%$ filter cake of $\mathrm{K}$ rank $+10 \%$ waste turbine oil;

$-90 \%$ filter cake of $\mathrm{K}$ rank $+10 \%$ waste transformer oil;

$-90 \%$ filter cake of $\mathrm{K}$ rank $+10 \%$ waste motor oil;

$-90 \%$ filter cake of $\mathrm{K}$ rank $+10 \%$ oil $\left(\rho=867 \mathrm{~kg} / \mathrm{m}^{3}\right)$;

$-90 \%$ filter cake of $\mathrm{K}$ rank $+10 \%$ oiled mixture;

$-90 \%$ filter cake of $\mathrm{G}$ rank $+10 \%$ waste compressor oil;

$-90 \%$ filter cake of $\mathrm{G}$ rank $+10 \%$ mazut;

$-90 \%$ filter cake of $\mathrm{G}$ rank $+10 \%$ waste motor oil;

$-90 \%$ filter cake of G rank + $10 \%$ waste turbine oil.

The stability of the fuel compositions was determined during the monitoring the process of separation of slurries. Tested slurry was poured into the measuring cylinder and was kept for 7-15 days. During the keeping process the transparent layer was formed on the surface of the tested slurry (fig. 1). Volume measurement of the separated transparent layer was carried out and the stability index was determined by the formula (1). 


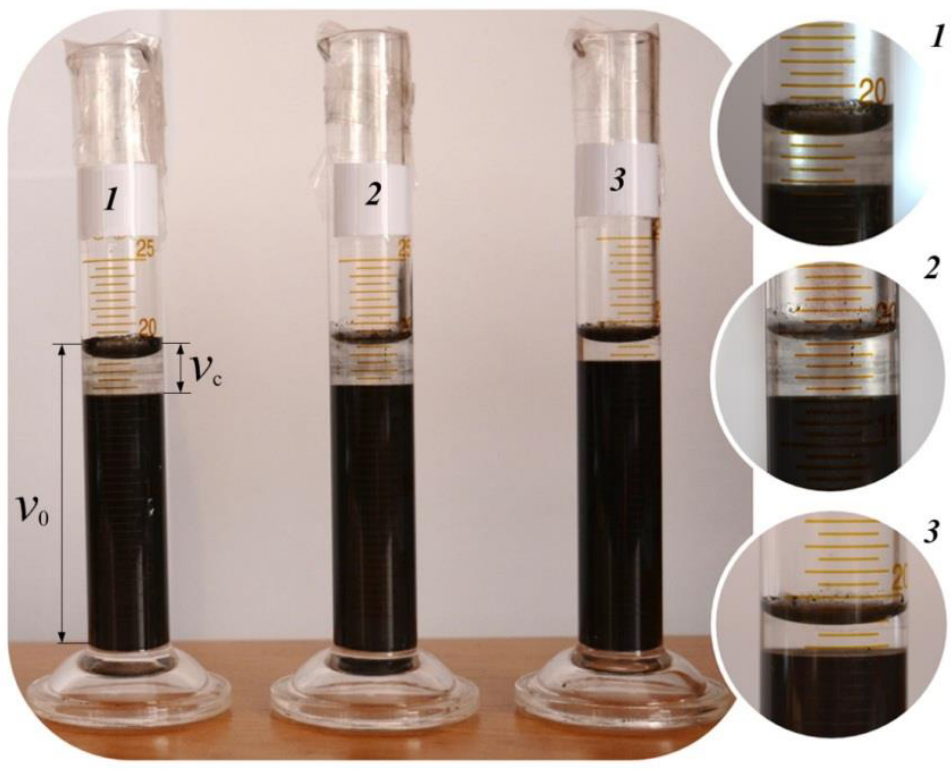

Fig. 1. The appearance of the investigated slurries with separated water layer.

\subsection{Evaluation of segmentation rate}

The evaluation of segmentation rate was carried out for the following compositions:

$-50 \%$ bituminous coal of $\mathrm{D}$ rank $+50 \%$ water;

$-50 \%$ brown coal of $\mathrm{B} 2$ rank $+50 \%$ water;

$-40 \%$ bituminous coal of $\mathrm{D}$ rank $+50 \%$ water $+10 \%$ waste turbine oil;

$-40 \%$ brown coal of B2 rank $+50 \%$ water $+10 \%$ waste turbine oil.

The procedure of evaluation of segmentation rate consists of several steps:

- preparation of weighed portions of the components in accordance with a given mass fraction in a slurry composition;

- determination of the mass of measuring cylinders for the storage of slurries;

- mixing the components of a slurry by homogenizer;

- the measuring cylinders were filled up with prepared fuel slurries;

- the prepared slurries were kept in the measuring cylinders for three days;

- the separated water layer was removed from the measuring cylinder and then the mass of separated water was measured;

- the separated water was dried and the coal concentration in the separated liquid layer was determined.

- the average segmentation rate was calculated by the formula (3).

\section{Result and discussion}

Figures 2 and 3 illustrate the experimental dependences of stability index on time of observation for investigated compositions of CWSs and CWSPs. 


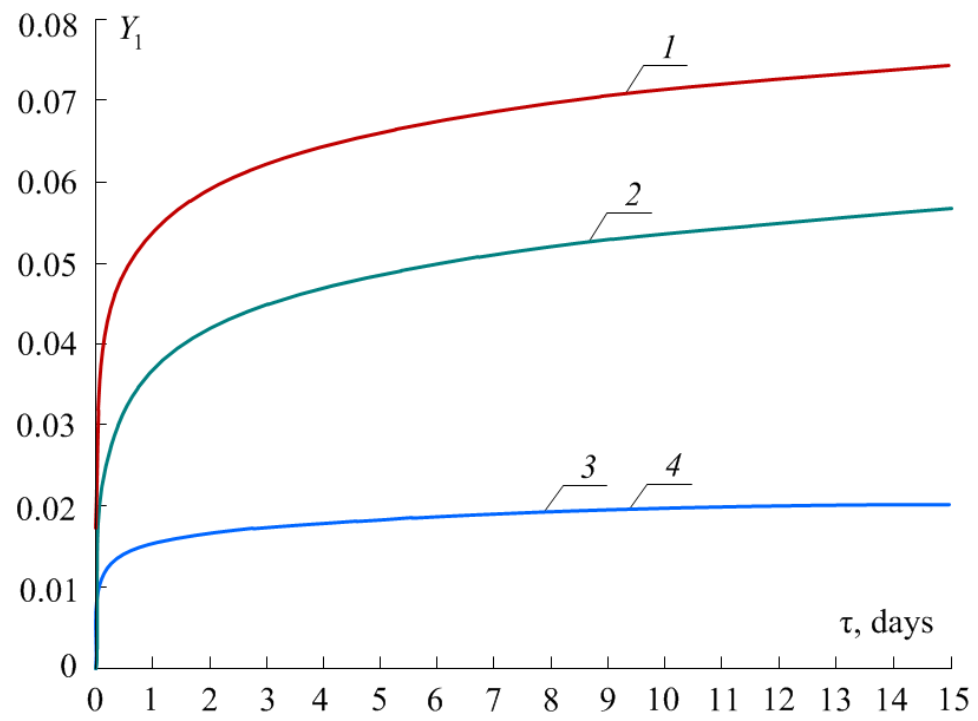

Fig. 2. The change of stability index in time: $1-100 \%$ filter cake of T rank; $2-100 \%$ filter cake of D rank; 3-100 \% filter cake of K rank; 4-100\% filter cake of SS rank.

As shown in figure 2, the slurries based on filter cakes of $\mathrm{K}$ and SS ranks are characterized by the highest structure stability (the lowest values of stability index) in comparison with the rest of the slurries. The intensive separation into layers of these CWS occurred during the first four days with the formation of water layer at the surface. After that the process of separation slowed down. The filter cakes of $\mathrm{T}$ and $\mathrm{D}$ ranks were less stable. The filter cake of $\mathrm{T}$ rank is characterized by the highest value of the stability index. The filter cake of $\mathrm{G}$ rank was sufficiently stable and did not separate into layers for 15 days.

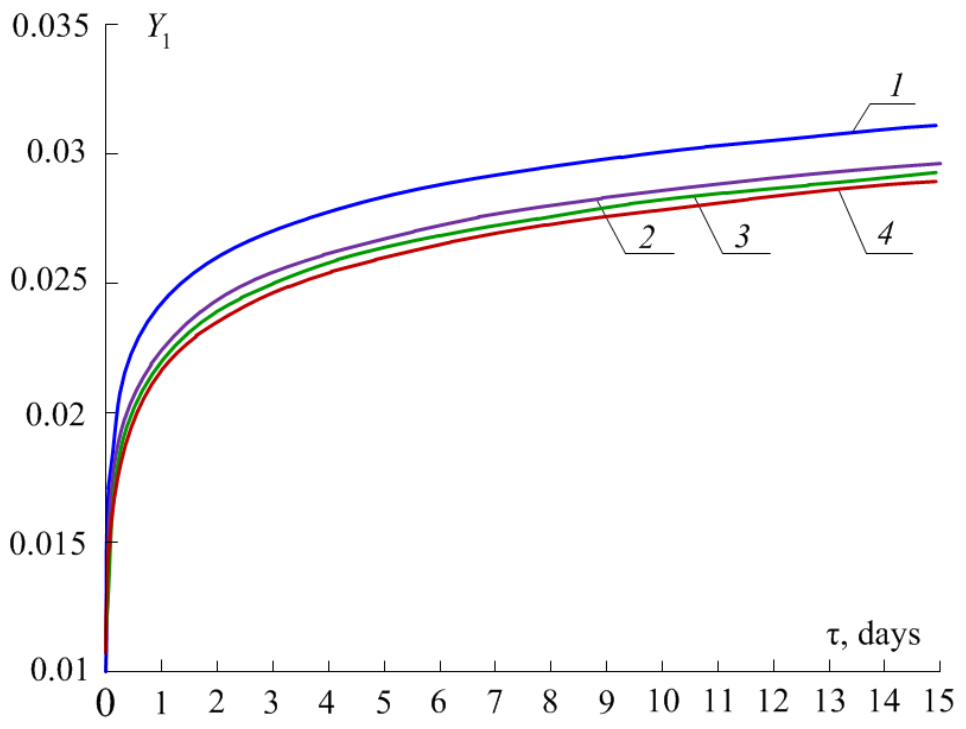

Fig. 3. The change of stability index in time: $1-90 \%$ filter cake of G rank, $10 \%$ waste compressor oil; 2 - $90 \%$ filter cake of G rank, $10 \%$ waste motor oil; 3 - $90 \%$ filter cake of G rank, $10 \%$ mazut; $4-90 \%$ filter cake of G rank, $10 \%$ waste turbine oil. 
The curves shown in figure 3 illustrate that for most compositions the stability index changes in the range from 0.015 to 0.025 . It should be noted, that the comparison of the stability indexes shown in fig. 2 and 3 allowed us to conclude, that the slurries based on filter cakes with additives of combustible liquid (fig. 3) are more stable than the CWSs without waste oil or mazut (fig. 2).

The slurries based on filter cake of $\mathrm{K}$ rank with additives of waste motor, turbine, transformer oils, oil and oiled mixture were characterized by high stability and did not separate into layers during the time of observation.

The influence of waste oils on the segmentation rate was determined for evaluation of the effectiveness of their using as stabilizing additives for CWSs and CWSPs. The results are presented in table 1.

Table 1. The evaluation of segmentation rate of CWSs and CWSPs.

\begin{tabular}{|l|c|c|c|c|}
\hline Compositions of slurries & $\begin{array}{c}50 \% \\
\text { brown coal } \\
\text { of B2 } \\
\text { rank, 50\% } \\
\text { water }\end{array}$ & $\begin{array}{c}50 \% \\
\text { bituminous } \\
\text { coal of D } \\
\text { rank, 50\% } \\
\text { water }\end{array}$ & $\begin{array}{c}40 \% \text { bituminous } \\
\text { coal of D rank, 50 } \\
\% \text { water, 10\% } \\
\text { waste turbine oil }\end{array}$ & $\begin{array}{c}40 \% \text { bituminous } \\
\text { coal of D rank, 50 } \\
\% \text { water, } 10 \% \\
\text { waste turbine oil }\end{array}$ \\
\hline Mass of water, g & 8.142 & 9.127 & 5.767 & 7.0814 \\
\hline Mass of coal, g & 8.142 & 9.127 & 4.612 & 5.665 \\
\hline Mass of oil, g & - & - & 1.153 & 1.4162 \\
\hline Initial slurry mass $\alpha_{0}, \mathrm{~g}$ & 16.284 & 18.254 & 11.532 & 14.163 \\
\hline Mass of liquid layer $\alpha_{1}, \mathrm{~g}$ & 3.26 & 3.267 & 1.044 & 4.456 \\
\hline $\begin{array}{l}\text { Initial concentration of } \\
\text { coal, } C_{0}, \%\end{array}$ & 50 & 50 & 40 & 2.63 \\
\hline $\begin{array}{l}\text { Ultimate concentration } \\
\text { of coal, } C_{1}, \%\end{array}$ & 6.17 & 17.01 & 7.372 & 2.134 \\
\hline $\begin{array}{l}\text { Average segmentation } \\
\text { rate, } \mathrm{r}, \% \text { /day }\end{array}$ & 5.850 & 3.936 & 1.641 & \\
\hline
\end{tabular}

The analysis of table 1 allows making a conclusion that segmentation rates for slurries based on brown or bituminous coal with the additive of waste turbine oil are almost twice smaller than the similar characteristic of slurries without oil additive. This indicates that the use of turbine oil had a stabilizing effect on the fuel composition by increasing its stability.

\section{Conclusion}

In accordance with the known experimental investigations we identified three main methods of determining stability of composite fuel slurries: the method of evaluation of separation (into layers) of the slurry [7-10], the method of penetration of the glass rod [1113] and translucence method $[14,15]$. In the present study the stability of CWSs and CWSPs compositions were determined by the method of evaluation of separation (into layers). Stability index and segmentation rate were chosen as integral characteristics of fuel stability. We found, that the addition of combustible liquid (for example, waste motor or turbine oil) to CWS provides more stable slurry (with high stability of structure). The limit (maximum) duration of conservation of sedimentation stability of investigated compositions was 15 days. The experiments illustrates that using inexpensive and 
affordable wastes (oiled mixtures, waste oils of different power plants, turbines, motors, transformers) is advisable for composite fuel slurry production.

\section{Acknowledgments}

This work supported by the Russian Science Foundation, project 15-19-10003.

\section{References}

1. A. Kijo-Kleczkowska, Fuel 90, 2 (2011)

2. E.G. Gorlov, Solid Fuel Chem. 38, 40 (2004)

3. V. Soloiu, J. Lewis, Y. Yoshihara, K. Nishiwaki, Energy 36, 4353 (2011)

4. P. Feng, L. Hao, C. Huo, Z. Wang, W. Lin, W. Song, Energy 66, 744 (2014)

5. K.N. Trubetskoi, A.S. Kondrat'ev, V.I. Murko, V.E. Zaidenvarg, G.A. Kassikhin, I.K. Nekhoroshii, Thermal engineering 55, 5 (2014)

6. S.N. D'yakov, A.V. Papin, A.V. Nevedrov, E.V. Zhbyr", Coke and Chemistry 55, 10 (2012)

7. Q. He, D. Xie, R. Xu, T. Wang, B. Hu, Fuel 159, 40 (2015)

8. H. Usui, J. Non-Newtonian Fluid Mech. 60, 2 (1995)

9. F.Yi, A. Gopan, R. L. Axelbaum, Journal of Fuel Chemistry and Technology 42, 10 (2014)

10. R. Xu, B. Hu, Q. He, J. Cai, Y. Pan, J. Shen, Fuel 85, 17 (2006)

11. R. Wang, J. Liu, F. Gao, J. Zhou, K. Cen, Fuel Processing Technology 104, 57 (2012)

12. X. Zhan, Z. Zhou, W. Kang, F. Wang, Fuel Processing Technology 91, 10 (2010)

13. M. Zhou, X. Qiu, D. Yang, H. Lou, X. Ouyang, Fuel Processing Technology 88, 4 (2007)

14. P. Li, D. Yang, H. Lou, X. Qiu, Journal of Fuel Chemistry and Technology 36, 5 (2008)

15. O. Mengual, G. Meunier, I. Cayre, K. Puech, P. Snabre, Colloids Surf. A 52, 1 (1999)

16. Z.H. Xia, L.Y. Lu, H. Wang, Spectroscopy and Spectral Analysis 35, 7 (2015)

17. C.K. Kim, G.J. Lee, M.K. Lee, C.K. Rhee, Arch. Metall. Mater. 60, 2 (2015) 